Research Article

\title{
Free Vibration Exploration of Rotating FGM Porosity Beams under Axial Load considering the Initial Geometrical Imperfection
}

\author{
Nguyen Thi Giang $\mathbb{D}$ \\ University of Transport Technology, 54 Trieu Khuc, Thanh Xuan, Hanoi, Vietnam \\ Correspondence should be addressed to Nguyen Thi Giang; giangnt@utt.edu.vn
}

Received 21 January 2021; Revised 23 February 2021; Accepted 4 March 2021; Published 18 March 2021

Academic Editor: Chiara Bedon

Copyright (c) 2021 Nguyen Thi Giang. This is an open access article distributed under the Creative Commons Attribution License, which permits unrestricted use, distribution, and reproduction in any medium, provided the original work is properly cited.

\begin{abstract}
In practice, some components in large structures such as the connecting rods between the rotating parts in the engines, turbines, and so on, can model as beam structures rotating around the fixed axis and subject to the axial compression load; therefore, the study of mechanical behavior to these structures has a significant meaning in practice. This paper analyzes the vibration responses of rotating FGM beams subjected to axial compressive loads, in which the beam is resting on the two-parameter elastic foundation, taking into account the initial geometrical imperfection. Finite element formulations are established by using the new shear deformation theory type of hyperbolic sine functions and the finite element method. The materials are assumed to be varied smoothly in the thickness direction of the beam based on the power-law function with the porosity. Verification problems are conducted to evaluate the accuracy of the theory, proposed mechanical structures, and the calculation programs coded in the MATLAB environment. Then, a parameter study is carried to explore the effects of geometrical and material properties on the vibration behavior of FGM beams, especially the influences of the rotational speed and axial compressive load.
\end{abstract}

\section{Introduction}

Functionally graded material (FGM) is commonly made of ceramic and metal in a certain proportion of ingredients; this is a new material that fully carries the characteristics of the material components such as good heat resistance, corrosive resistance, and withstanding thermal stress. Therefore, studying the mechanical behavior of structures made of FG materials has great practical value, especially in designing, manufacturing, and using them in the most effective way. Also, large mechanical systems such as helicopter blades, aircraft, and ship propellers and even nanosize devices such as microturbines may include blade-like structures that occur in rotational movements, where they can be considered as rotating beam structures. Hence, investigations of rotating integrated beam structures play a very important role in science. There have been a number of research projects and exploration results on these issues. Saito and Otomi [1] researched the stability and vibration of a beam under axial and tangential loads, where the analysis is based on the Timoshenko beam theory, and the effects of the attached mass are expressed with Dirac delta functions. Esmailzadeh and Ohadi [2] introduced a solution for stability and vibration response analysis of a beam subjected to both tangential and axial loads using the Frobenius method and Timoshenko beam theory, in which the axial force is assumed to be tangential to the axis of the beam-column. Sloss et al. [3] used Green's function to find the solution of the vibration control problem of piezoelectric beams subjected to axial load. Zhang et al. [4] studied the vibration problem of carbon nanotubes subjected to axial load using Bernoulli-Euler theory. Alkharabsheh and Younis [5] investigated the effect of axial forces on the static behavior and the fundamental natural frequency of electrostatically actuated MEMS arches using Euler-Bernoulli theory. Babilio [6] employed the Galerkin procedure to study the dynamics of an FGM beam under axial load, in which Taylor expansion was used to establish the partial differential equation. Barry 
et al. [7] gave out equations of motion of a beam under axial loads; then, the solution of the vibration response of this beam was introduced, in which this beam was attached to a mass-spring-mass system. Farokhi and Ghayesh [8] researched the nonlinear bending and resonant behavior of a microarch based on Euler-Bernoulli theory and the Galerkin method. Ghannadiasl and Mofid [9] used Green function to investigate the free vibration of a beam subjected to axial loads using Timoshenko beam theory and an analytical method. Nejati et al. [10] employed the generalized differential quadrature approach to explore the buckling and vibration behavior of the FGM beam reinforced with carbon nanotubes. A two-node $C^{1}$ beam element was used by Thuc et al. [11] to analyze the free vibration of composite beams under axial load using a four-unknown shear and normal deformation theory. Waddar et al. [12] showed an experimental study of buckling and the dynamic response of the cenosphere reinforced epoxy composite core sandwich beam with sisal fabric/epoxy composite facings subjected to axial load. Zhao et al. [13] presented the exact solutions of the forced transverse vibration of a coupled Timoshenko double-beam system under compressive axial load based on Timoshenko beam theory and Green's functions; the solution could be suitable for any boundary conditions. Szymczak and Kujawa [14] presented an exact formulation of the frequency for free torsional vibration analysis of laminated beams subjected to axial load. Xu et al. [15] used the energy principle in conjunction with the Rayleigh-Ritz procedure to investigate the flexural vibration and its power flow of an axially loaded beam with arbitrary boundary and nonuniform elastic foundation. Brahimi-Mamaghani et al. [16] employed an analytical approach to finding the solution of dynamic and vibration stability of a viscoelastic FGM beam under axial load, where the Laplace transform and a Galerkin discretization scheme were combined to capture the solution. Khosravi et al. [17] used the first-order shear deformation plate theory to investigate the nonaxisymmetric buckling behaviour of isotropic homogeneous annular plates subjected to simultaneous effects of uniform temperature rise and constant angular speed.

Recently, the explorations of mechanical responses of rotating beam structures have also been in interest and researched by scientists. Khosravi et al. [18] employed Timoshenko beam theory and von Kármán type of kinematic assumptions to examine the influence of uniform temperature elevation on the vibration of rotating composite beams reinforced with carbon nanotubes which may lead to instability. Timoshenko beam theory and von Kármán type of kinematic assumptions were also used by Khosravi and his coworkers [19] to study the thermal buckling of rotating carbon nanotube-reinforced composite beams. Kiani et al. [20] investigated the buckling behaviour of an isotropic homogeneous rotating annular plate subjected to uniform compression on both inner and outer edges. Bagheri et al. [21] researched the free vibration treatment of pre- and postbuckled rotating functionally graded beams using the Euler-Bernoulli beam theory. Hosseini et al. [22] analyzed the buckling and postbuckling of rotating clamped-clamped functionally graded beams due to the interaction between the thermal environment and the rotation based on the Euler-Bernoulli beam theory. From these works, one can see that the boundary condition has a significant influence on the mechanical responses of the rotating beam, especially to the natural frequencies as well as the vibration mode shapes of this structure. In addition, boundary details and material degradation also have a significant effect on these responses, which can be better understood in $[23,24]$.

In the fabrication process, there can be many types of defects, in which the porosities are easy to appear, dramatically altering the mechanical response of these structures. There have been a number of scientific studies on the free and forced vibration responses and static bending of beams and plates made of FG materials with pore defects [25-32].

From the published research studies, readers can find that previous studies only mentioned the mechanical behavior of porosity beam structures made of FG materials, whether or not resting on elastic foundations, while some works investigated the effect of initial compressive force with rotational movement around one fixed axis, where these studies have not fully presented beams with both pore defects and imperfections subjected to both axial compression and elastic foundation effect. Besides, this proposed mathematical model is close to the technical reality models, which can help to guide in designing, manufacturing, and using them effectively.

Therefore, this work is about to focus on these proposed problems by using the finite element method and a new type of shear deformation theory in the form of hyperbolic sine functions. This is a simple theory, which takes into account the effect of shear strain without any shear correction factors, and it is an advantage of computational theory in this work. This is the first work using this beam theory to solve the problem of free vibration of rotating FGM beams considering both shape and material defects, thereby giving the influence of different parameters on the free vibration response of this structure, especially the influence of the rotational movement. This is the new point of this work, in which the calculation results are of great value for the designers and users as mentioned above.

The rest of this work is structured as follows. Finite element formulations for free vibration analysis of rotating FGM beams resting on two-parameter elastic foundations are fully presented in Section 2, in which the initial geometrical imperfection and the porosity are considered. Verification examples are introduced in Section 3. $\mathrm{Nu}-$ merical results and discussion are abundantly presented in Section 4. Section 5 draws out some main important highlight explorations of this paper.

\section{Finite Element Model of Rotating FGM Beams with Geometrical Imperfection and Porosity}

This work is about to focus on the vibration analysis of the FGM beam rotating with the rotational speed $\Theta$, in which one side of the beam is at distance $r$ from a fixed axis $\Phi$. The 
beam has an initial geometrical imperfection and the porosity. The structure is subjected to an axial compressive load $N_{0}$ and resting on the two-parameter elastic foundation with two parameters $k_{w}$ and $k_{s}$ as shown in Figure 1. The geometrical dimensions are the length $L$, width $b$, and thickness $h$.

The beam is made from two main components including ceramic (denoted as $c$ ) and metal (denoted as $m$ ) with the corresponding proportions $V_{c}$ and $V_{m}$, which are calculated by the following function [33-38]:

$$
\begin{aligned}
V_{c} & =\left(\frac{z}{h}+\frac{1}{2}\right)^{n} ; \\
V_{m} & =1-V_{c} \text { with } n \geq 0,
\end{aligned}
$$

in which $z$ is the thickness coordinate variable with $-(h / 2) \leq z \leq(h / 2)$ and $n$ is the volume fraction gradient index and its variation.

Then, the mechanical properties are changed in the $z$ direction based on the power-law distribution as

$$
\begin{aligned}
& E(z)=E_{m}+\left(E_{c}-E_{m}\right)\left(\frac{1}{2}+\frac{z}{h}\right)^{n}-\frac{\alpha}{2}\left(E_{c}+E_{m}\right) \\
& \rho(z)=\rho_{m}+\left(\rho_{c}-\rho_{m}\right)\left(\frac{1}{2}+\frac{z}{h}\right)^{n}-\frac{\alpha}{2}\left(\rho_{c}+\rho_{m}\right) \\
& \nu(z)=\nu_{m}+\left(\nu_{c}-\nu_{m}\right)\left(\frac{1}{2}+\frac{z}{h}\right)^{n}-\frac{\alpha}{2}\left(\nu_{c}+\nu_{m}\right),
\end{aligned}
$$

where $E$ is Young's modulus, $\rho$ is the density, $\nu$ is Poisson's ratio, and $\alpha$ is a porosity volume fraction $(\alpha<1)$.

There have been many shear deformation theories to investigate the mechanical responses of beam structures, where each one has its advantages. Recently, a new type of shear deformation theory has been developed and used widely, which is hyperbolic sine functions $[39,40]$. This work also employs this new theory to establish the finite element equations of free vibration problems of rotating FGM beams. So, the displacement field at any point $(x, z)$ within the beam has the following form:

$$
\left\{\begin{array}{l}
u_{x}(x, z)=u_{x 0}(x, y)-z \frac{\partial u_{z b}}{\partial x}-f(z) \frac{\partial u_{z s}}{\partial x} \\
u_{z}(x, z)=u_{z b}+u_{z s}+u_{z i m}(x)
\end{array}\right.
$$

where $f(z)=z-h \sinh (z / h)+z \cosh (1 / 2)$.

The expressions of strain components of the beam are calculated as

$$
\begin{aligned}
\varepsilon_{x} & =\frac{\partial u_{x}}{\partial x}=\frac{\partial u_{x 0}}{\partial x}-z \frac{\partial^{2} u_{z b}}{\partial x^{2}}-g(z) \frac{\partial^{2} u_{z s}}{\partial x^{2}}+\frac{\mathrm{d} u_{z i m}}{\mathrm{~d} x} \frac{\partial\left(u_{z b}+u_{z s}\right)}{\partial x} \\
& =\frac{\partial u_{x 0}}{\partial x}+z\left(-\frac{\partial^{2} u_{z b}}{\partial x^{2}}\right)+g(z)\left(-\frac{\partial^{2} u_{z s}}{\partial x^{2}}\right)+\frac{\mathrm{d} u_{z i m}}{\mathrm{~d} x} \frac{\partial\left(u_{z b}+u_{z s}\right)}{\partial x} \\
& =\varepsilon_{x 0}+z \varepsilon_{x b}+g(z) \varepsilon_{x s}+\varepsilon_{x i m} \\
\gamma_{x}^{z} & =\frac{\partial g(z)}{\partial z} \frac{\partial u_{z s}}{\partial x}=\frac{\partial g(z)}{\partial z} \gamma_{x z 0},
\end{aligned}
$$

in which

$$
\begin{aligned}
\varepsilon_{x 0}=\frac{\partial u_{x 0}}{\partial x}, & \\
\varepsilon_{x b} & =\left(-\frac{\partial^{2} u_{z b}}{\partial x^{2}}\right), \\
\varepsilon_{x s} & =\left(-\frac{\partial^{2} u_{z s}}{\partial x^{2}}\right), \\
\varepsilon_{i m} & =\frac{\mathrm{d} u_{z i m}}{\mathrm{~d} x} \frac{\partial\left(u_{z b}+u_{z s}\right)}{\partial x} .
\end{aligned}
$$

For the linear problem, the stress-strain relation according to Hooke's law is expressed as follows:

$$
\left\{\begin{array}{l}
T_{x}=E(z) \varepsilon_{x}, \\
\wp_{x z}=\frac{E(z)}{2(1+\nu(z))} \gamma_{x z},
\end{array}\right.
$$

where $T_{x}$ is the normal stress and $\wp_{x z}$ is the shear stress.

The elastic strain generates the elastic energy of the FGM beam which is calculated as 


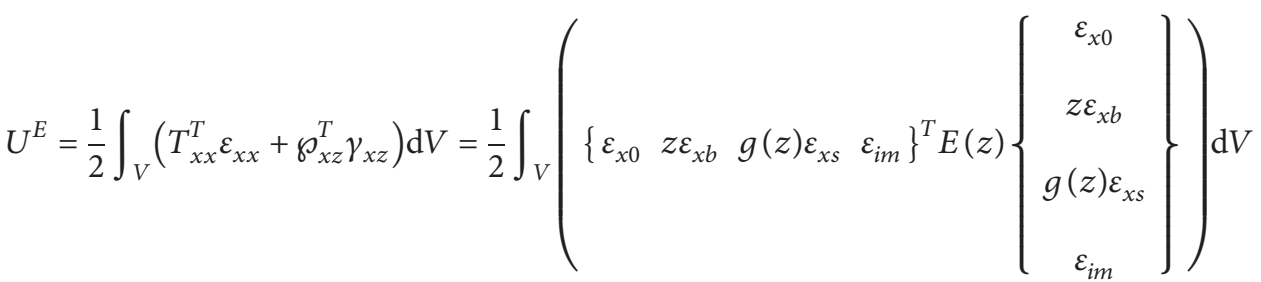

$$
\begin{aligned}
& +\frac{1}{2} \int_{V}\left(\left\{\frac{\partial g(z)}{\partial z} \gamma_{x}^{z 0}\right\}^{T} \frac{E(z)}{2(1+\nu(z))}\left\{\frac{\partial g(z)}{\partial z} \gamma_{x}^{z 0}\right\}\right) \mathrm{d} V= \\
& \frac{1}{2} \int_{V}\left(\begin{array}{c}
\varepsilon_{x 0}^{T} E(z) \varepsilon_{x 0}+\varepsilon_{x 0}^{T} z E(z) \varepsilon_{z b}+\varepsilon_{x 0}^{T} g(z) E(z) \varepsilon_{x s}+\varepsilon_{x 0}^{T} E(z) \varepsilon_{x i m} \\
\varepsilon_{x b}^{T} E(z) z \varepsilon_{x 0}+\varepsilon_{x b}^{T} E(z) z^{2} \varepsilon_{x b}+\varepsilon_{x b}^{T} E(z) z g(z) \varepsilon_{x s}+\varepsilon_{x b}^{T} E(z) z \varepsilon_{x i m} \\
\varepsilon_{x s}^{T} E(z) g(z) \varepsilon_{x 0}+\varepsilon_{x s}^{T} E(z) z g(z) \varepsilon_{x b}+\varepsilon_{x s}^{T} E(z) g^{2}(z) \varepsilon_{x s}+\varepsilon_{x s}^{T} E(z) g(z) \varepsilon_{x i m} \\
\varepsilon_{x i m}^{T} E(z) \varepsilon_{x 0}+\varepsilon_{x i m}^{T} E(z) z \varepsilon_{x b}+\varepsilon_{x i m}^{T} E(z) g(z) \varepsilon_{x s}+\varepsilon_{x i m}^{T} E(z) \varepsilon_{x i m}
\end{array}\right) \mathrm{d} V \\
& +\frac{1}{2} \int_{V}\left(\left(\frac{\partial g(z)}{\partial z}\right)^{2} \frac{E(z)}{2(1+\nu(z))} \gamma_{x z 0}^{T} \gamma_{x z 0}\right) \mathrm{d} V \\
& K=\frac{1}{2} \int_{V} \rho(z)\left(\left(\frac{\partial \dot{u}_{x}}{\partial t}\right)^{T}\left(\frac{\partial \dot{u}_{x}}{\partial t}\right)+\left(\frac{\partial \dot{u}_{z}}{\partial t}\right)^{T}\left(\frac{\partial \dot{u}_{z}}{\partial t}\right)\right) d V .
\end{aligned}
$$

The work done by the external compressive load is expressed as follows [41]:

$$
U^{A x}=\frac{1}{2} \int_{V}\left(N_{0}\left(\frac{\partial\left(\left(w_{b}+w_{s}\right)\right)}{\partial x}\right)^{2}\right) \mathrm{d} x
$$

The energy of the elastic foundation is calculated as

$$
U^{F}=\frac{1}{2} b \int_{L}\left(k_{w}\left(w_{b}+w_{s}\right)^{2}+k_{s}\left(\frac{\partial\left(\left(w_{b}+w_{s}\right)\right)}{\partial x}\right)^{2}\right) \mathrm{d} x
$$

When the FGM beam is rotating around one fixed axis with the rotational speed $\Theta$, the potential energy of this beam generated by the rotational movement is calculated as $[41,42]$

$$
U^{\Theta}=\frac{1}{2} \int_{L}\left(P_{\Theta}(x)\left(\frac{\partial\left(w_{b}+w_{s}\right)}{\partial x}\right)^{2}\right) \mathrm{d} x,
$$

with the centrifugal force $P_{\Theta}$ [42].

$$
P_{\Theta}=\frac{1}{2} \int_{S}\left(\rho(z) \Theta^{2}\left[r(L-x)+\frac{1}{2}\left(L^{2}-x^{2}\right)\right]\right) \mathrm{d} S,
$$

and $\rho(z)$ is the density of the material.

The kinetic energy of the beam is expressed as
To determine the equilibrium equation of the FGM beam, this work uses Hamilton's principle as follows:

$$
\delta \int_{t_{1}}^{t_{2}}\left(K-U^{E}-U^{F}-U^{R o}-U^{A x}\right) \mathrm{d} t=0 .
$$

Herein, this paper uses a two-node beam element, where each node contains five degrees of freedom:

$$
\psi_{e}=\sum_{i=1}^{2}\left\{\begin{array}{c}
u_{x 0} \\
u_{z b i} \\
u_{z s i} \\
\left(\frac{\partial u_{z b}}{\partial x}\right)_{i} \\
\left(\frac{\partial u_{z s}}{\partial x}\right)_{i}
\end{array}\right\},
$$

in which the displacement components at each point in the beam element are calculated through Lagrange and Hermite interpolation functions $N_{i}$ and $H_{i}$ : 


$$
\begin{aligned}
& u_{x 0}=\sum_{i=1}^{2} N_{i} u_{0 i}=\mathbf{N}_{x u} \psi_{e} \\
& u_{z b}=\sum_{i=1}^{2}\left\{H_{i} u_{z b i}+H_{i+1}\left(\frac{\partial u_{z b}}{\partial x}\right)_{i}\right\}=\mathbf{H}_{b} \boldsymbol{\psi}_{e} \\
& u_{z s}=\sum_{i=1}^{2}\left\{H_{i} u_{z s i}+H_{i+1}\left(\frac{\partial u_{z s}}{\partial x}\right)_{i}\right\}=\mathbf{H}_{s} \psi_{e} \\
& \frac{\partial u_{z b}}{\partial x}=\sum_{i=1}^{2}\left\{\frac{\partial H_{i}}{\partial x} u_{z b i}+\frac{\partial H_{i+1}}{\partial x}\left(\frac{\partial u_{z b}}{\partial x}\right)_{i}\right\}=\mathbf{H}_{b x} \boldsymbol{\psi}_{e} \\
& \frac{\partial u_{z s}}{\partial x}=\sum_{i=1}^{2}\left\{\frac{\partial H_{i}}{\partial x} u_{z s i}+\frac{\partial H_{i+1}}{\partial x}\left(\frac{\partial u_{z s}}{\partial x}\right)_{i}\right\}=\mathbf{H}_{s x} \boldsymbol{\psi}_{e}, \\
& \frac{\partial^{2} u_{z b}}{\partial x^{2}}=\sum_{i=1}^{2}\left\{\frac{\partial^{2} H_{i}}{\partial x^{2}} u_{z b i}+\frac{\partial^{2} H_{i+1}}{\partial x^{2}}\left(\frac{\partial u_{z b}}{\partial x}\right)_{i}\right\}=\mathbf{H}_{b 2 x} \boldsymbol{\psi}_{e} \\
& \frac{\partial^{2} u_{z s}}{\partial x^{2}}=\sum_{i=1}^{2}\left\{\frac{\partial^{2} H_{i}}{\partial x^{2}} u_{z s i}+\frac{\partial^{2} H_{i+1}}{\partial x^{2}}\left(\frac{\partial u_{z s}}{\partial x}\right)_{i}\right\}=\mathbf{H}_{s 2 x} \psi_{e}
\end{aligned}
$$

Equation (15) can be rewritten in the matrix form as follows:

$$
\psi=\left\{\begin{array}{c}
u_{z 0} \\
u_{z b} \\
u_{z s} \\
\left(\frac{\partial u_{z b}}{\partial x}\right) \\
\left(\frac{\partial u_{z s}}{\partial x}\right)
\end{array}\right\}=\left[\begin{array}{c}
\mathbf{N}_{x u} \\
\mathbf{H}_{b} \\
\mathbf{H}_{s} \\
\mathbf{H}_{b x} \\
\mathbf{H}_{s x}
\end{array}\right] \psi_{e}=\mathbf{H} \psi_{e}
$$

Strain components are expressed according to the nodal displacement as

$$
\left\{\begin{array}{l}
\varepsilon_{0 x}=\frac{\partial u_{x 0}}{\partial x}=\frac{\partial \mathbf{N}_{x u}}{\partial x} \psi_{e}=\mathbf{B}_{u} \psi_{e}, \\
\varepsilon_{x b}=-\frac{\partial^{2} u_{z b}}{\partial x^{2}}=-\mathbf{H}_{b 2 x} \psi_{e}=\mathbf{B}_{b} \psi_{e}, \\
\varepsilon_{x s}=-\frac{\partial^{2} u_{z s}}{\partial x^{2}}=-\mathbf{H}_{s 2 x} \psi_{e}=\mathbf{B}_{s} \psi_{e}, \\
\varepsilon_{x i m}=\frac{\partial\left(u_{z b}+u_{z s}\right)}{\partial x} \frac{\mathrm{d} u_{z i m}}{\mathrm{~d} x}=\frac{\mathrm{d} u_{z i m}}{\mathrm{~d} x}\left(\mathbf{H}_{b}+\mathbf{H}_{s x} \psi_{e} .\right.
\end{array}\right.
$$


And now, the elastic energy of the FGM beam element has the following expression:

$$
\begin{aligned}
& U_{e}^{E}=\frac{1}{2} \psi_{e}^{T} \int_{V}\left(\begin{array}{c}
\mathbf{B}_{u}^{T} E \mathbf{B}_{u}+\mathbf{B}_{u}^{T} z E \mathbf{B}_{b}+\mathbf{B}_{u}^{T} g(z) E \mathbf{B}_{s}+\mathbf{B}_{u}^{T} E \mathbf{B}_{i m} \\
\mathbf{B}_{b}^{T} E z \mathbf{B}_{u}+\mathbf{B}_{b}^{T} E z^{2} \mathbf{B}_{b}+\mathbf{B}_{b}^{T} E z g(z) \mathbf{B}_{s}+\mathbf{B}_{b}^{T} E z \mathbf{B}_{i m} \\
\mathbf{B}_{s}^{T} E g(z) \mathbf{B}_{u}+\mathbf{B}_{s}^{T} E z g(z) \mathbf{B}_{b}+\mathbf{B}_{s}^{T} E g^{2}(z) \mathbf{B}_{s}+\mathbf{B}_{s}^{T} E g(z) \mathbf{B}_{i m} \\
\mathbf{B}_{i m}^{T} E \mathbf{B}_{u}+\mathbf{B}_{i m p}^{T} E z \mathbf{B}_{b}+\mathbf{B}_{i m p}^{T} E g(z) \mathbf{B}_{s}+\mathbf{B}_{i m}^{T} E \mathbf{B}_{i m}
\end{array}\right) \mathrm{d} V \psi_{e} \\
& +\frac{1}{2} \psi_{e}^{T} \int_{V}\left(\left(\frac{\partial g(z)}{\partial z}\right)^{2} \frac{E}{2(1+\nu)} \mathbf{H}_{s x}^{T} \mathbf{H}_{s x}\right) \mathrm{d} V \boldsymbol{\psi}_{e} \\
& =\frac{1}{2} \psi_{e}^{T} \int_{V}\left(\begin{array}{c}
\mathbf{B}_{u}^{T} E \mathbf{B}_{u}+\mathbf{B}_{u}^{T} z E \mathbf{B}_{b}+\mathbf{B}_{u}^{T} g(z) E \mathbf{B}_{s}+\mathbf{B}_{u}^{T} E \mathbf{B}_{i m} \\
\mathbf{B}_{b}^{T} E z \mathbf{B}_{u}+\mathbf{B}_{b}^{T} E z^{2} \mathbf{B}_{b}+\mathbf{B}_{b}^{T} E z g(z) \mathbf{B}_{s}+B_{b}^{T} E z \mathbf{B}_{i m} \\
\mathbf{B}_{s}^{T} E g(z) \mathbf{B}_{u}+\mathbf{B}_{s}^{T} E z g(z) \mathbf{B}_{b}+\mathbf{B}_{s}^{T} E g^{2}(z) \mathbf{B}_{s}+\mathbf{B}_{s}^{T} E g(z) \mathbf{B}_{i m} \\
\mathbf{B}_{i m}^{T} E \mathbf{B}_{u}+\mathbf{B}_{i m p}^{T} E z \mathbf{B}_{b}+\mathbf{B}_{i m p}^{T} E f(z) \mathbf{B}_{s}+\mathbf{B}_{i m}^{T} E \mathbf{B}_{i m}
\end{array}\right) d V \psi_{e} \\
& +\frac{1}{2} \psi_{e}^{T} \int_{V}\left(\left(\frac{\partial g(z)}{\partial z}\right)^{2} \frac{E}{2(1+\nu)} \mathbf{H}_{s x}^{T} \mathbf{H}_{s x}\right) d V \boldsymbol{\psi}_{e}
\end{aligned}
$$

Equation (18) can be rewritten in the matrix form as

$$
U_{e}^{E}=\frac{1}{2} \psi_{e}^{T} \mathbf{K}_{e}^{E} \psi_{e}
$$

The energies of the centrifugal inertia force and the elastic foundation are defined as follows:

$$
\begin{aligned}
U_{e}^{F} & =\frac{1}{2} \psi_{e}^{T}\left(b \int_{L}\left(\begin{array}{c}
k_{w}\left(\mathbf{H}_{b}+\mathbf{H}_{s}\right)^{T}\left(\mathbf{H}_{b}+\mathbf{H}_{s}\right) \\
+k_{s}\left(\mathbf{H}_{b x}+\mathbf{H}_{s x}\right)^{T}\left(\mathbf{H}_{b x}+\mathbf{H}_{s x}\right)
\end{array}\right) \mathrm{d} x\right) \\
\psi_{e} & =\frac{1}{2} \psi_{e}^{T} \mathbf{K}_{e}^{F} \psi_{e} \\
U_{e}^{R} & =\frac{1}{2} \psi_{e}\left(b \int_{L}\left\{P_{\Theta}(x)\left(\mathbf{H}_{b x}+\mathbf{H}_{s x}\right)^{T}\left(\mathbf{H}_{b x}+\mathbf{H}_{s x}\right)\right\} \mathrm{d} x\right) \\
\psi_{e} & =\frac{1}{2} \psi_{e}^{T} \mathbf{K}_{e}^{R} \psi_{e} .
\end{aligned}
$$

The energy expression due to the axial compressive load has the following form:

$$
\begin{aligned}
U^{A x} & =\frac{1}{2} \psi_{e}^{T}\left\{b \int_{L}\left(N_{0}\left(\mathbf{H}_{b x}+\mathbf{H}_{s x}\right)^{T}\left(\mathbf{H}_{b x}+\mathbf{H}_{s x}\right)\right) \mathrm{d} x\right\} \\
\psi_{e} & =\frac{1}{2} \psi_{e}^{T} \mathbf{K}_{e}^{A x} \psi_{e} .
\end{aligned}
$$

The kinetic energy expression of the beam element is calculated as follows:

$$
\begin{aligned}
& K_{e}=\frac{1}{2} \int_{V}\left(\dot{\psi}_{e}^{T} \rho(z) \dot{\psi}_{e}\right) \mathrm{d} V=\frac{1}{2} \dot{\psi}_{e}^{T}\left(\int_{V}\left(\mathbf{H}^{T} \mathbf{H}\right) \mathrm{d} V\right) \\
& \dot{\psi}_{e}=\frac{1}{2} \dot{\psi}_{e}^{T}\left(\mathbf{M}_{e}\right) \dot{\psi}_{e},
\end{aligned}
$$

in which $\mathbf{M}_{e}=\int_{V} \rho(z)\left(\mathbf{H}^{T} \mathbf{H}\right) \mathrm{d} V$ is the element stiffness matrix.

Substituting equations (18)-(20) into equation (13), the equation to get the fundamental frequency, as well as the vibration mode shape of the rotating FGM beam, is obtained as follows:

$$
\left\{\sum_{e}\left(\mathbf{K}_{e}^{E}+\mathbf{K}_{e}^{F}+\mathbf{K}_{e}^{R}-\mathbf{K}_{e}^{A x}\right)-\omega^{2} \sum_{e} \mathbf{M}_{e}\right\} \sum_{e} \psi_{e}=0 .
$$

Equation (23) demonstrates that all components relating to rotational speed, elastic foundation parameter, initial geometrical imperfection, and axial compressive loads are presented in the equation for finding the fundamental vibration response of the FGM beam, which is completely different from traditional problems; this makes the computation more difficult in comparison with previous publications.

Each side of the beam is under the following boundary conditions: 


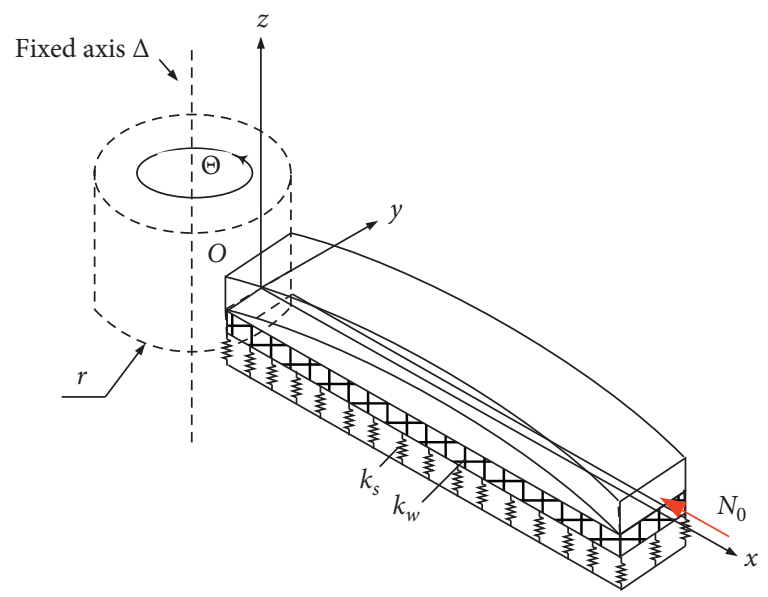

(a)

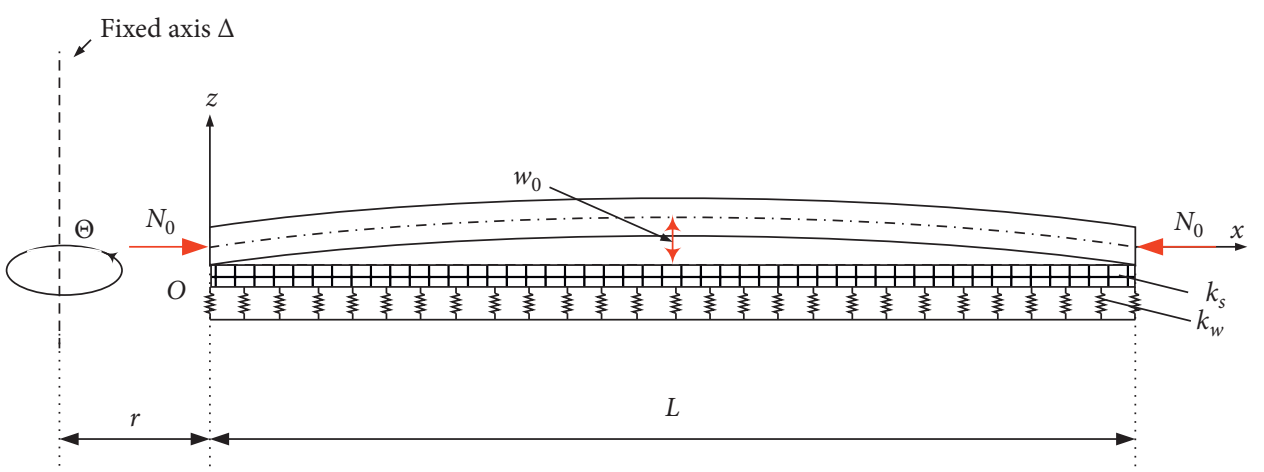

(b)

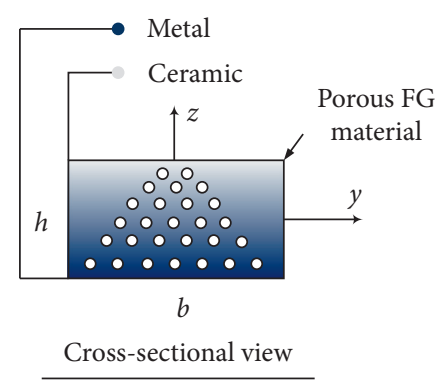

(c)

FIGURE 1: A rotating FGM beam subjected to axial compressive loads: (a) 3D view, (b) $x \mathrm{Oz}$ view, and (c) cross-sectional view.

Simply supported (denoted as S):

$$
\begin{gathered}
u_{0}=0, \\
w_{b}=0, \\
w_{s}=0 .
\end{gathered}
$$

Clamped (denoted as C):

$$
\begin{aligned}
u_{0} & =0, \\
w_{b} & =0, \\
w_{s} & =0, \\
\frac{\partial w_{b}}{\partial x} & =0, \\
\frac{\partial w_{s}}{\partial x} & =0 .
\end{aligned}
$$

This paper employs three boundary conditions for calculations of FGM beams.

One side is clamped, and the other side is free: C-F.

Fully simply supported beam: S-S.

Fully clamped beam: C-C.

\section{Verification Examples}

This section conducts five examples to evaluate the accuracy of the proposed theory and mathematical models, in which the numerical data of these examples are compared with those of other trustful publications.

Example 1. This example compares the frequency of the homogeneous beam under the axial compressive load. Geometrical and material properties are the length $L$, cross section $b x h, L / h=100, E=380 \mathrm{GPa}, \nu=0.3$, and $\rho=3960 \mathrm{~kg} / \mathrm{m}^{3}$. The beam is subjected to an axial compressive load $N_{0}$ with $\bar{N}=N_{0} L^{2} / \pi^{2} E I_{0}=0.6$. The nondimensional frequency is defined by the formula $\widetilde{\omega}=\omega \sqrt{\rho b h L^{4} / E I_{0}}$ (with $I_{0}=b h^{3} / 12$ ). The results obtained from this work, exact expressions [43, 44], and FEM modeling [45] are listed in Table 1, in which they are calculated with different meshes. It can be seen that when the mesh size increases, the calculation results ensure the necessary convergence. The computational results in this work with the 8-element mesh are different from the results of the same mesh in reference [45]. The reason is that document [45] used the first-order shear deformation theory of Timoshenko. And for the 8-element mesh, the accuracy is acceptable; therefore, this mesh will be used for all the following related investigations. 
TABLE 1: First three nondimensional frequencies $(\widetilde{\omega})$ of the beam under the axial load $\bar{N}=0.6$.

\begin{tabular}{|c|c|c|c|c|c|c|c|c|c|}
\hline \multirow{2}{*}{$\mathrm{BC}$} & \multirow{2}{*}{ Mode } & \multirow{2}{*}{ Exact $[43]$} & \multirow{2}{*}{ Exact $[44]$} & \multirow{2}{*}{ FEM with 8 elements [45] } & \multicolumn{5}{|c|}{ This work } \\
\hline & & & & & 4 elements & 6 elements & 8 elements & 10 elements & 12 elements \\
\hline \multirow{3}{*}{ S-S } & 1 & 6.24 & - & 6.24 & 6.247 & 6.243 & 6.242 & 6.242 & 6.241 \\
\hline & 2 & 36.40 & - & 36.41 & 36.505 & 36.402 & 36.383 & 36.377 & 36.375 \\
\hline & 3 & 85.81 & - & 85.93 & 61.891 & 85.924 & 85.768 & 85.721 & 85.703 \\
\hline \multirow{3}{*}{$\mathrm{C}-\mathrm{C}$} & 1 & - & 13.01 & 13.01 & 13.018 & 13.006 & 13.003 & 13.003 & 13.003 \\
\hline & 2 & - & 47.35 & 47.38 & 47.493 & 47.356 & 47.323 & 47.313 & 47.309 \\
\hline & 3 & - & 101.54 & 101.73 & 101.053 & 101.630 & 101.450 & 101.384 & 101.358 \\
\hline
\end{tabular}

Example 2. Next, this problem compares the results of porosity FGM beams from this work and Chebyshev collocation solution (CCS) [46]. The ratio $L / h$ obtains the values of 5,10 , and 20; the porosity parameter $\vartheta$ is 0 and 0.2 . Geometrical and material characteristics of the fully clamped FGM beam are $E_{\mathrm{c}}=380 \mathrm{GPa}, \nu_{c}=0.3, \rho_{c}=3960 \mathrm{~kg} / \mathrm{m}^{3}$, $E_{\mathrm{m}}=70 \mathrm{GPa}, \nu_{m}=0.3$, and $\rho_{m}=2702 \mathrm{~kg} / \mathrm{m}^{3}$. The comparative nondimensional frequencies $\widehat{\omega}=\omega L \sqrt{\rho_{m} / E_{m}}$ are presented in Table 2. It can be observed that the data have a very good similarity.

Example 3. Now, the frequency of the fully simply supported FGM $\left(\mathrm{Al} / \mathrm{Al}_{2} \mathrm{O}_{3}\right)$ beam resting on the two-parameter elastic foundation is considered. Geometrical and material properties are the length $L$, thickness $h, L / h=100$, width $b, E_{m}=70 \mathrm{GPa}, \rho_{m}=2702 \mathrm{~kg} / \mathrm{m}^{3}, E_{c}=380 \mathrm{GPa}$, and $\rho_{m}=396 \mathrm{~kg} / \mathrm{m}^{3}$. Two nondimensional elastic foundation parameters are defined as follows:

$$
\left\{\begin{array}{l}
\bar{K}_{w}=\frac{K_{1} L^{4}}{E_{m} I}, \\
\bar{K}_{s}=\frac{K_{2} L^{2}}{E_{m} I \pi^{2}},
\end{array}\right.
$$

with

$$
I=\frac{b h^{3}}{12} .
$$

The nondimensional frequency of the beam is calculated as follows:

$$
\widehat{\omega}=\omega_{1} \frac{L^{2}}{h} \sqrt{\frac{\rho_{m}}{E_{m}}} .
$$

Table 3 presents the comparative first frequencies of the beam between this work and the analytical method [47]. One can see that, with the 10 elements, the accuracy is acceptable; therefore, this work will use this mesh for all the following related explorations.

Example 4. Next, this example compares the frequency of the S-S beam with an initial geometrical imperfection. The beam has the following geometrical and material parameters: $L=288.7 h, h=0.02 \mathrm{~m}, b=0.04 \mathrm{~m}, E=971 \mathrm{GPa}$, and mass density $\rho=2300 \mathrm{~kg} / \mathrm{m}^{3}$. The initial imperfection of the beam is $w_{\text {im }}(x)=J_{0} \sin (\pi x)$, in which $J_{0}$ is the amplitude of the imperfection. The nondimensional frequency and the initial imperfection coefficient $\varsigma_{0}$ are defined as follows:

$$
\begin{aligned}
\omega * * & =\omega_{1} \sqrt{\frac{12 \rho L^{4}}{E h^{2}}}, \\
\varsigma_{0} & =\frac{J_{0}}{L} .
\end{aligned}
$$

The numerical data obtained from this work and the pseudo-arc-length continuation technique [48] in the case of increasing the value of $\varsigma_{0}$ are shown in Figure 2. It can be seen that the data meet a good agreement.

Example 5. Finally, this last example carries the verification of the nondimensional frequency of the cantilever rotating beam with the speed $\chi$. Consider a beam with the following geometrical and material parameters: length $L$, thickness $h=b=L / 100, \quad r=0, E=70 \mathrm{GPa}$, and mass density $\rho=2700 \mathrm{~kg} / \mathrm{m}^{3}$. The nondimensional frequency $\widetilde{\omega}_{i}$ is normalized as follows:

$$
\bar{\omega}_{i}=\omega_{i} L^{2} \sqrt{\frac{12 \rho}{E h^{2}}} .
$$

The first three nondimensional frequencies of the rotating beam with different values of the speed ratio $\bar{\xi}=L^{2} \Theta$ $\sqrt{\left(12 \rho / E h^{2}\right)}$ obtained from this work, an exact solution [49], a new dynamic modeling method (DMM) [50], and an isogeometric analysis [42] are presented in Table 4.

\section{Numerical Results}

This section carries out the vibration analysis of the rotating FGM porosity beam resting on the two-parameter elastic foundation subjected to the preaxial compressive load, where the initial geometrical imperfection is taken into calculations. Consider a beam with the following geometrical and material properties: length $L$, cross section $b x h$, $E_{\mathrm{c}}=380 \mathrm{GPa}, \quad v_{c}=0.3, \quad \rho_{c}=3960 \mathrm{~kg} / \mathrm{m}^{3}, \quad E_{m}=70 \mathrm{GPa}$, $\nu_{m}=0.3$, and $\rho_{m}=2702 \mathrm{~kg} / \mathrm{m}^{3}$. The imperfection of the beam is $w_{0}(x)=Y_{0} \sin (\pi x)$, in which $G_{0}$ is the amplitude of the imperfection, and the imperfection ratio $\mu_{0}=Y_{0} / L$. The 
TABle 2: The first nondimensional frequency $(\widehat{\omega})$ of the FGM beam depends on the porosity parameter $\vartheta$.

\begin{tabular}{|c|c|c|c|c|c|c|c|}
\hline \multirow{2}{*}{$\vartheta$} & \multirow{2}{*}{$L / h$} & \multicolumn{2}{|c|}{$n=0.2$} & \multicolumn{2}{|c|}{$n=0.5$} & \multicolumn{2}{|c|}{$n=1.0$} \\
\hline & & CCS [46] & This work & CCS [46] & This work & CCS [46] & This work \\
\hline \multirow{3}{*}{0} & 5 & 1.8823 & 1.8892 & 1.7392 & 1.7416 & 1.5844 & 1.5820 \\
\hline & 10 & 1.0884 & 1.0896 & 0.9992 & 1.0022 & 0.9056 & 0.9109 \\
\hline & 20 & 0.5691 & 0.5693 & 0.5213 & 0.5217 & 0.4716 & 0.4724 \\
\hline \multirow{3}{*}{0.2} & 5 & 1.9205 & 1.9272 & 1.7402 & 1.7395 & 1.5210 & 1.5129 \\
\hline & 10 & 1.1092 & 1.1105 & 0.9956 & 0.9989 & 0.8606 & 0.8661 \\
\hline & 20 & 0.5797 & 0.5799 & 0.5186 & 0.5192 & 0.4465 & 0.4477 \\
\hline
\end{tabular}

TABLE 3: The first nondimensional frequencies $(\widehat{\omega})$ of the beam resting on the two-parameter elastic foundation, $\bar{K}_{w}=10, \bar{K}_{s}=1, \mathrm{~S}-\mathrm{S}$.

\begin{tabular}{|c|c|c|c|c|c|c|c|c|}
\hline & \multicolumn{8}{|c|}{$a / h=100$} \\
\hline & \multirow{2}{*}{$n$} & \multirow{2}{*}{ Mode } & \multirow{2}{*}{ Exact [47] } & \multicolumn{5}{|c|}{ This work } \\
\hline & & & & 6 elements & 8 elements & 10 elements & 12 elements & 14 elements \\
\hline \multirow{9}{*}{$\begin{array}{l}\text { Without the elastic foundation } \\
\bar{K}_{w}=0 \\
\bar{K}_{s}=0\end{array}$} & \multirow{3}{*}{0} & 1 & 5.483 & 5.483 & 5.483 & 5.483 & 5.483 & 5.483 \\
\hline & & 2 & 21.933 & 21.931 & 21.924 & 21.922 & 21.921 & 21.921 \\
\hline & & 3 & 49.350 & 49.389 & 49.318 & 49.296 & 49.288 & 49.284 \\
\hline & \multirow{4}{*}{1} & 1 & 4.221 & 4.220 & 4.220 & 4.220 & 4.220 & 4.220 \\
\hline & & 2 & 16.884 & 16.884 & 16.879 & 16.877 & 16.876 & 16.876 \\
\hline & & 3 & 37.989 & 38.030 & 37.975 & 37.958 & 37.952 & 37.949 \\
\hline & & 1 & 3.852 & 3.851 & 3.851 & 3.851 & 3.851 & 3.851 \\
\hline & \multirow[t]{3}{*}{2} & 2 & 15.407 & 15.408 & 15.403 & 15.402 & 15.401 & 15.401 \\
\hline & & 3 & 34.666 & 34.707 & 34.657 & 34.641 & 34.635 & 34.633 \\
\hline \multirow{9}{*}{$\begin{array}{l}\text { With the elastic foundation } \\
\bar{K}_{w}=10 \\
\bar{K}_{s}=1\end{array}$} & & 1 & 6.015 & 6.014 & 6.014 & 6.014 & 6.014 & 6.014 \\
\hline & \multirow[t]{2}{*}{0} & 2 & 22.445 & 22.442 & 22.436 & 22.434 & 22.433 & 22.433 \\
\hline & & 3 & 49.858 & 49.891 & 49.824 & 49.803 & 49.796 & 49.792 \\
\hline & \multirow{4}{*}{1} & 1 & 5.008 & 5.007 & 5.007 & 5.007 & 5.007 & 5.007 \\
\hline & & 2 & 17.666 & 17.664 & 17.660 & 17.659 & 17.658 & 17.658 \\
\hline & & 3 & 38.77 & 38.801 & 38.753 & 38.738 & 38.732 & 38.729 \\
\hline & & 1 & 4.752 & 4.752 & 4.752 & 4.752 & 4.752 & 4.752 \\
\hline & \multirow[t]{2}{*}{2} & 2 & 16.316 & 16.315 & 16.311 & 16.310 & 16.310 & 16.309 \\
\hline & & 3 & 35.577 & 35.606 & 35.564 & 35.550 & 35.545 & 35.543 \\
\hline
\end{tabular}

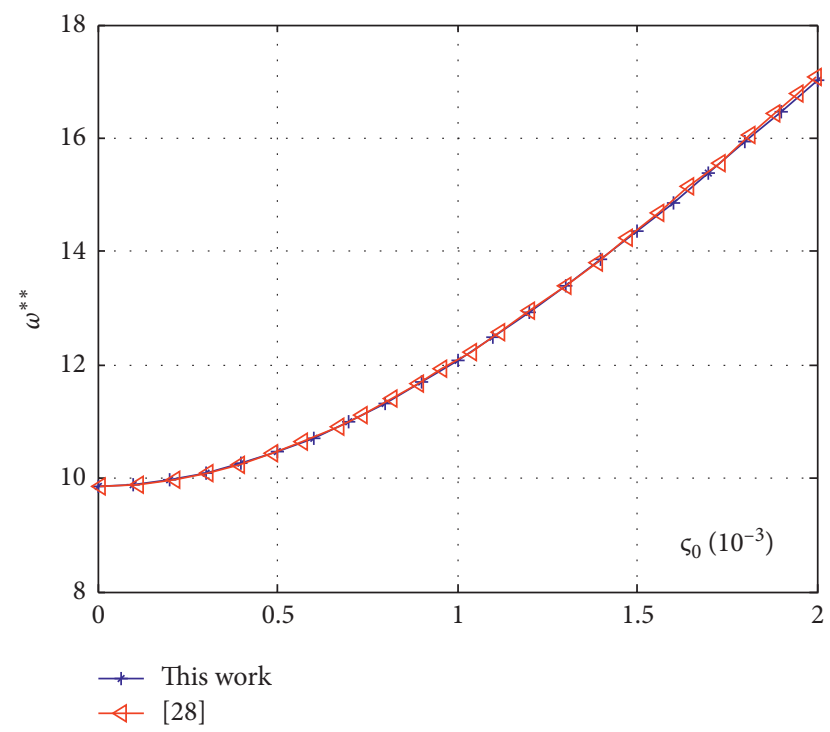

Figure 2: The dependence of the first nondimensional frequency of the beam with the initial geometrical imperfection on $\varsigma_{0}$. 
TABLE 4: The dependence of the first three nondimensional frequencies $\left(\bar{\omega}_{i}\right)$ of the cantilever rotating beam on $\vartheta$.

\begin{tabular}{|c|c|c|c|c|c|}
\hline \multirow{2}{*}{ Mode } & \multirow{2}{*}{ Method } & \multicolumn{4}{|c|}{ Rotational speed ratio $\bar{\xi}$} \\
\hline & & $\bar{\xi}=0$ & $\bar{\xi}=3$ & $\bar{\xi}=6$ & $\bar{\xi}=12$ \\
\hline \multirow{4}{*}{$\widetilde{\omega}_{1}$} & This work & 3.5161 & 4.6790 & 7.0734 & 12.6098 \\
\hline & Exact [49] & 3.5160 & 4.7973 & 7.3604 & 13.1702 \\
\hline & DMM [50] & 3.5160 & 4.7973 & 7.3604 & - \\
\hline & Isogeometric [42] & 3.5118 & 4.7733 & 7.3276 & - \\
\hline \multirow{4}{*}{$\widetilde{\omega}_{2}$} & This work & 22.0247 & 23.1197 & 26.1110 & 36.4500 \\
\hline & Exact [49] & 22.0345 & 23.3203 & 26.8091 & 37.6031 \\
\hline & DMM [50] & - & - & - & - \\
\hline & Isogeometric [42] & - & - & - & - \\
\hline \multirow{4}{*}{$\widetilde{\omega}_{3}$} & This work & 61.6254 & 62.7602 & 66.0242 & 77.4512 \\
\hline & Exact [49] & 61.6972 & 62.9850 & 66.6840 & 79.6145 \\
\hline & DMM [50] & - & - & - & - \\
\hline & Isogeometric [42] & - & - & - & - \\
\hline \multirow{4}{*}{$\widetilde{\omega}_{4}$} & This work & 120.647 & 121.843 & 125.348 & 138.295 \\
\hline & Exact [49] & 120.902 & 122.236 & 126.140 & 140.534 \\
\hline & DMM [50] & - & - & - & - \\
\hline & Isogeometric [42] & - & - & - & - \\
\hline
\end{tabular}

nondimensional frequency and other parameters are normalized as follows:

$$
\begin{aligned}
\omega_{i}^{*} & =\omega_{i} L \sqrt{\frac{\rho_{m}}{E_{m}}}, \\
K_{w}^{*} & =\frac{k_{w} L^{4}}{\bar{D}_{m}}, \\
K_{s}^{*} & =\frac{k_{s} L^{2}}{\bar{D}_{m}}, \\
\delta & =L^{2} \Theta \sqrt{\frac{12 \rho_{m}}{E_{m} h_{0}^{2}}}, \\
\bar{D}_{m} & =\frac{E_{m} h_{0}^{3}}{12}, \\
N^{*} & =\frac{N_{0} L^{2}}{\pi^{2} E_{m} I_{0}}, \\
I_{0} & =\frac{b h_{0}^{3}}{12}, \\
h_{0} & =\frac{L}{20} .
\end{aligned}
$$

4.1. Effect of the Rotational Speed. Firstly, the influence of the rotational speed on the free vibration response of the rotating FGM beam is investigated. The rotational speed $\Theta$ is increased gradually so that the coefficient $\delta$ changes in a range of 0 to 10 ; the volume fraction index $n$ obtains the values from 0 to 10 ; other parameters are $L / h=20$, imperfection ratio $\lambda_{0}=0.001$, axial compressive load $N^{*}=0.5$, $K_{w}^{*}=5, K_{s}^{*}=1$, distance ratio $r / L=1$, and $\vartheta=0.2$. Figures $3-5$ present the dependence of the first frequency of the beam on the rotational speed ratio $\delta$ and the volume fraction index $n$. The first four vibration mode shapes of the S-S and C-C rotating FGM beams with the speed ratio $\delta=0$ and 8 are presented in Figures 6 and 7. These figures point out the following.

When the rotational speed increases, nondimensional frequencies of the beam in the case of both boundary conditions (S-S and C-C) increase. This is because as the rotational speed of the beam increases, the inertial force component increases; therefore, the stiffness matrix of the FGM beam is increased by the addition of this inertial component. The change of the first nondimensional frequency of the structure depends strongly on the boundary conditions and the volume fraction index $n$. For the S-S boundary, when $n$ increases, the first frequency of the beam decreases. In contrast, for the C-C beam, when $n$ increases, the first frequency of the beam decreases sharply at first, then its value reaches the minimum point, and it increases gradually.

Besides, the rotational speed has a strong effect on the vibration mode shape of the beam, especially the first vibration mode shape. Also, due to the appearance of the inertial force, the first vibration mode shape is no longer symmetrical through the position $x=L / 2$. The influence of the rotational speed on the vibration mode shapes depends strongly on the boundary conditions; for the S-S boundary condition, the influence level is more pronounced than the beam under the $\mathrm{C}-\mathrm{C}$ boundary condition.

4.2. Influence of the Axial Load. This section is about to capture the effect of the axial compressive load on the vibration behavior of the FGM beam. The axial compressive load is changed so that the nondimensional load $N^{*}$ obtains the values from 0 to 0.8 . The dependence of the first frequency of the FGM beam on the axial load $N^{*}$ and the volume fraction index $n$ is presented in Table 5 , and the dependence of the first frequency on the axial load $N^{*}$ and the rotational speed is presented in Table 6. As the axial 


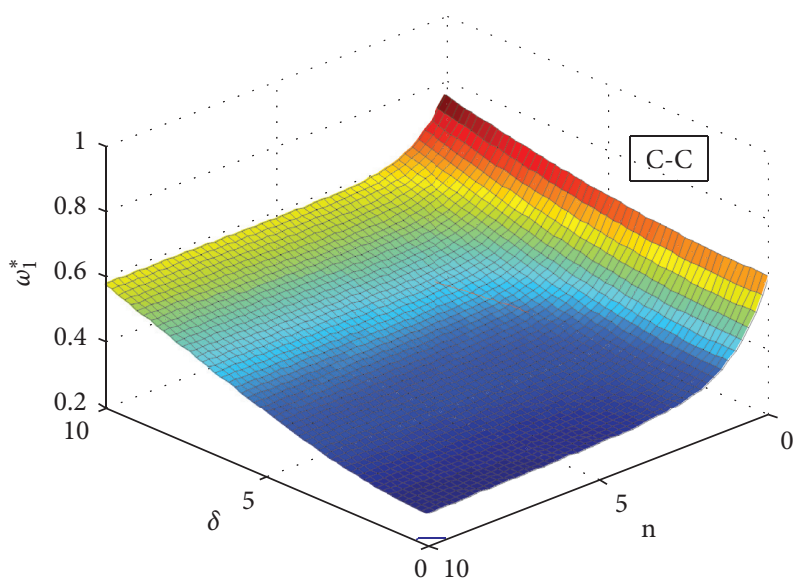

(a)

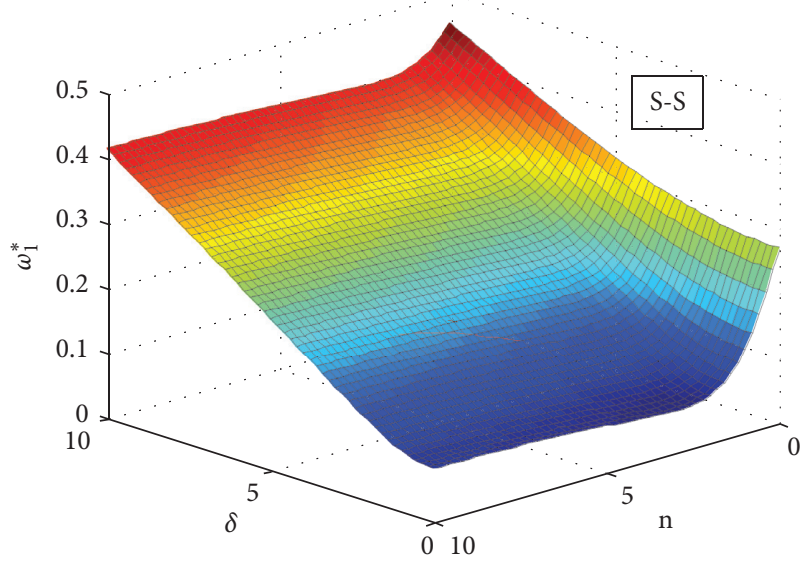

(b)

Figure 3: The dependence of the first nondimensional frequency of the rotating FGM beam on the volume fraction index $n, \lambda_{0}=0.001$, $K_{w}^{*}=5$, and $K_{s}^{*}=1$. (a) C-C. (b) S-S.

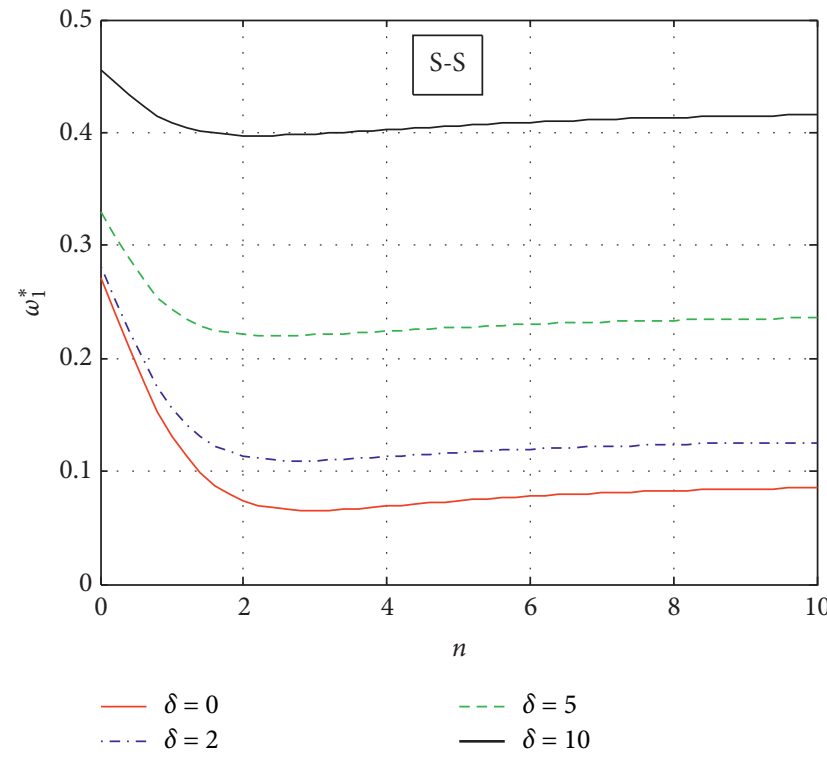

(a)

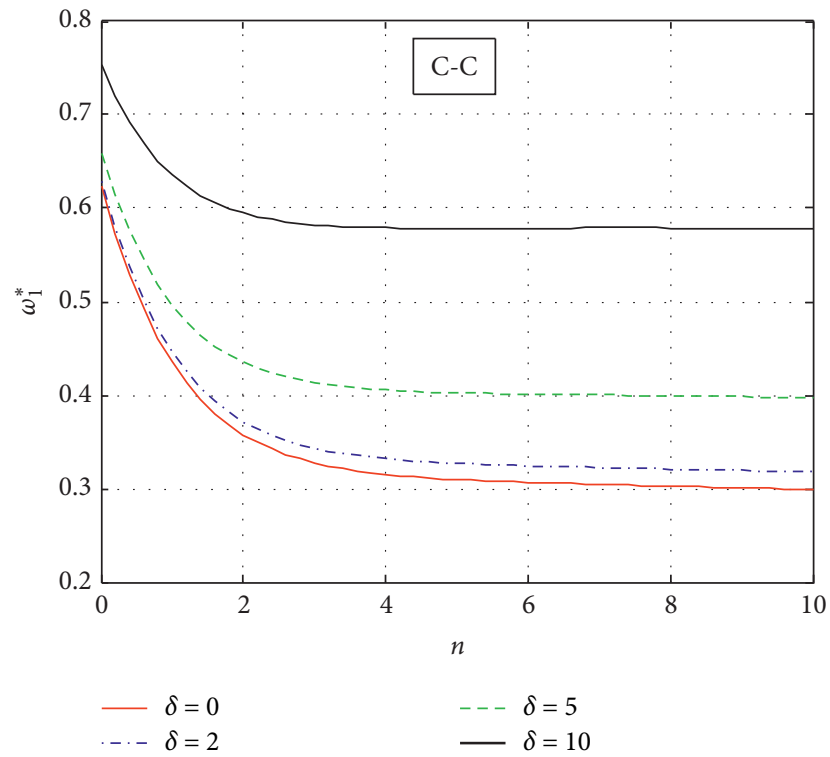

(b)

FIGURE 4: The dependence of the first nondimensional frequency of the rotating FGM beam on the volume fraction index $n$ and the rotational speed, $\lambda_{0}=0.001, K_{w}^{*}=5$, and $K_{s}^{*}=1$. (a) S-S. (b) C-C.

compressive load increases, the frequency of the FGM beam decreases; this is because as the compressive load increases, the stiffness matrix of this beam decreases. Table 7 shows that when the value of the compression load $N^{*}$ is increased, the first nondimensional frequency changes the most, while the higher-order frequencies change slightly.

4.3. Influence of the Thickness of the FGM Beam. Consider an FGM beam with $L / h$ varying from 5 to 80 , imperfect parameter $\lambda_{0}=0.001, N^{*}=0.5, K_{w}^{*}=5, K_{s}^{*}=1$, distance ratio $r /$ $L=1$, and volume fraction index $n=0.2$. The dependence of the first nondimensional frequency of the FGM beam on $L / h$ and $\alpha$ is presented in Table 8 , and the dependence of the first nondimensional frequency on $L / h$ and the rotational speed parameter $\delta$ is presented in Table 9. Table 10 shows the dependence of the first six nondimensional frequencies of the FGM beam on $L / h$. These numerical results point out the following:

When the thickness of the FGM beam is reduced, the first nondimensional frequency of the beam decreases; however, the strongest decrease of the first frequency is when the thickness decreases from $L / h=5$ to $L / h=10$. The frequency of the $\mathrm{C}-\mathrm{C}$ beam is always greater than that of the S-S beam in the same other conditions.

When increasing parameter $\alpha$, the first nondimensional frequency of the beam increases; this is because when 


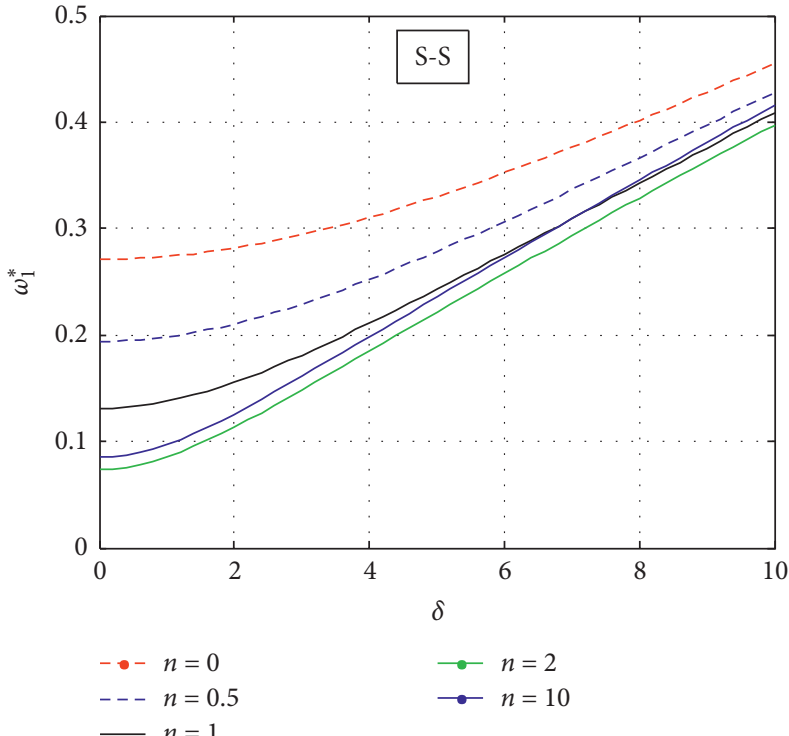

(a)

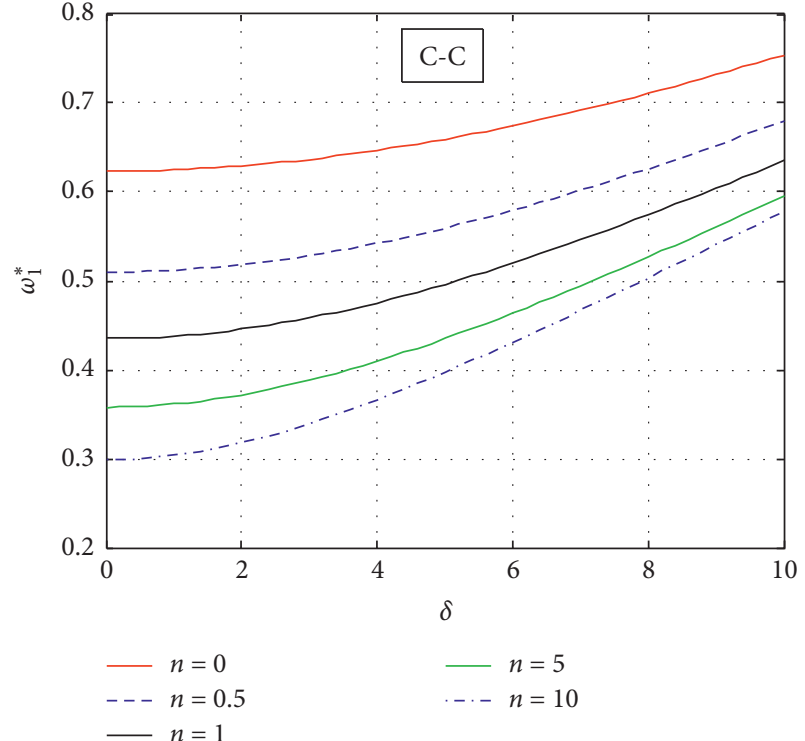

(b)

FIGURE 5: The dependence of the first nondimensional frequency of the rotating FGM beam on the volume fraction index $n$ and the rotational speed, $\lambda_{0}=0.001, K_{w}^{*}=5$, and $K_{s}^{*}=1$.

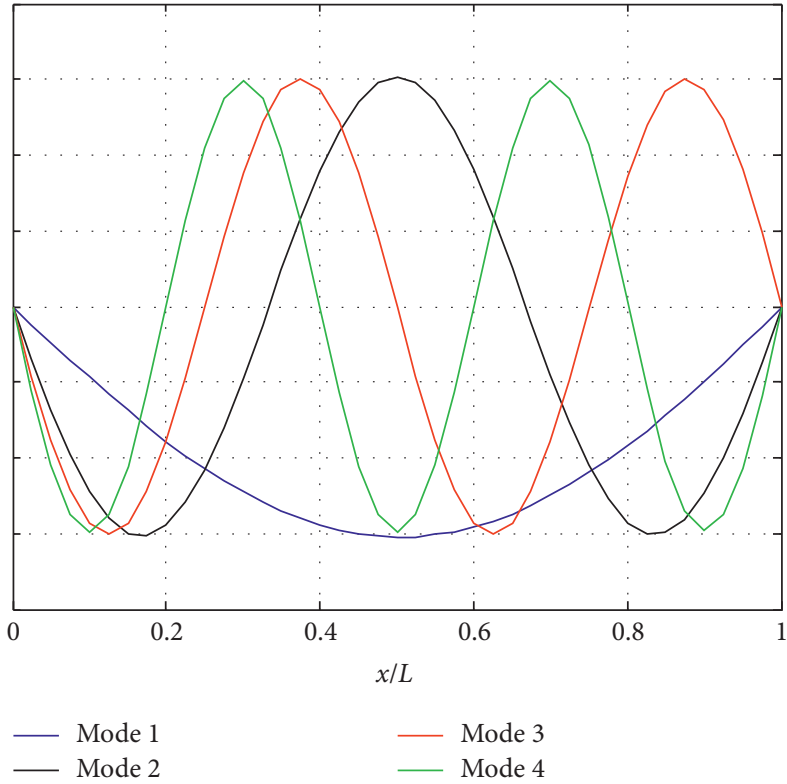

(a)

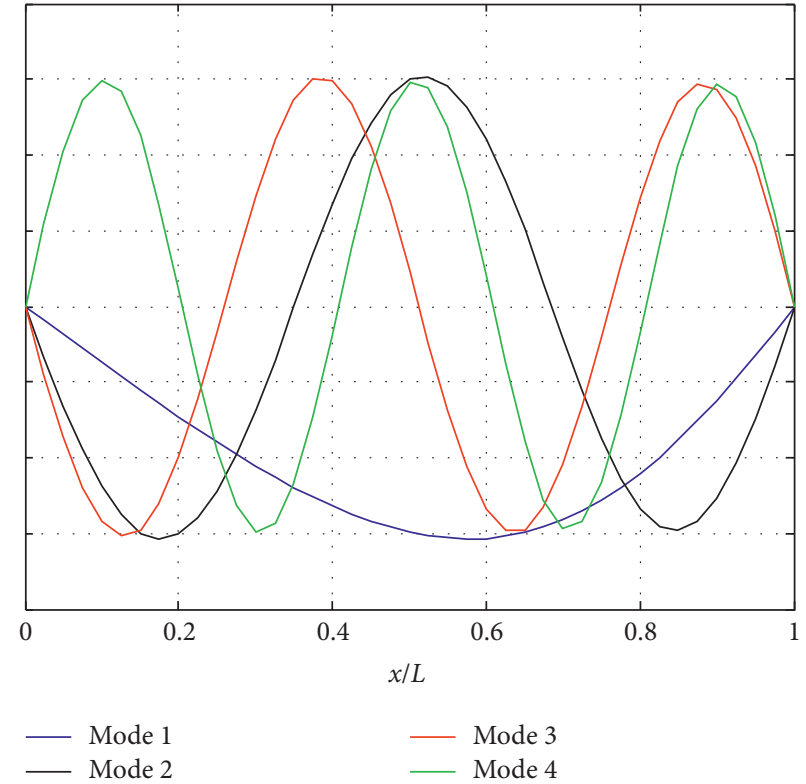

(b)

Figure 6: The dependence of the first four vibration mode shapes of the rotating FGM beam on the rotational speed, S-S, $n=1$, and $N^{*}=0.5$. (a) S-S, $\delta=0$, and $r=0$. (b) S-S, $\eta=8$, and $r / L=1$. 


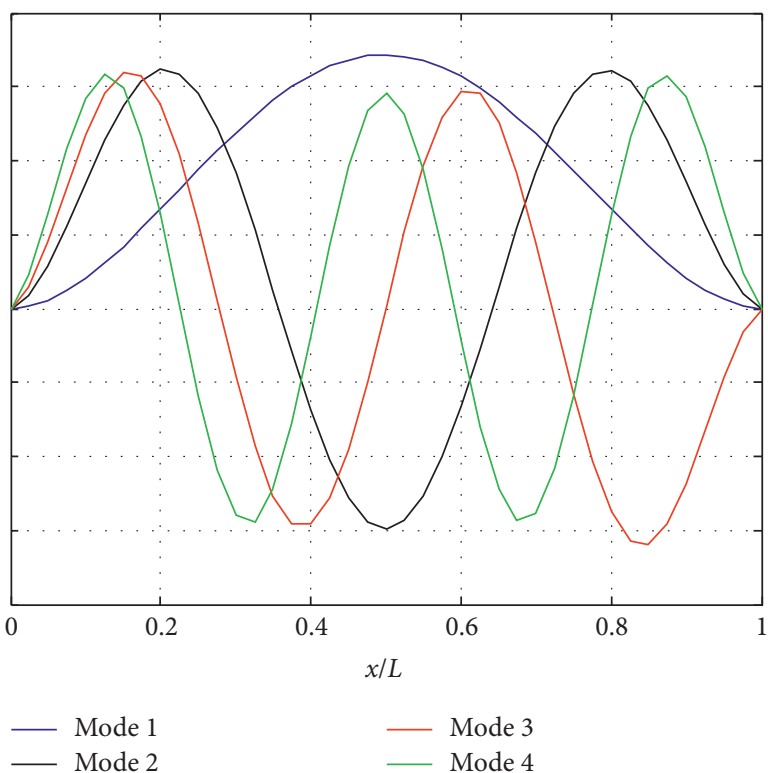

(a)

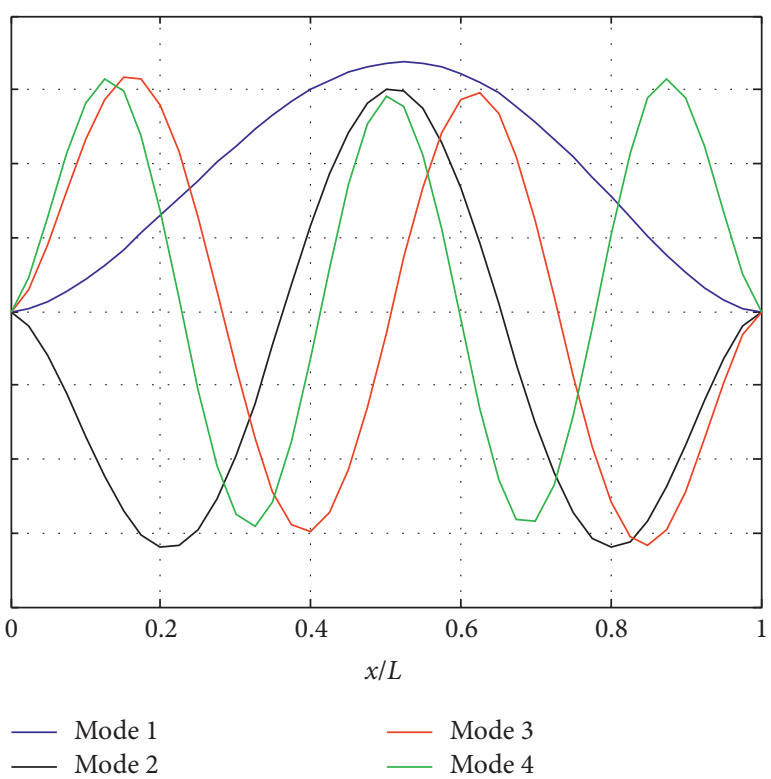

(b)

FIGURE 7: The dependence of the first four vibration mode shapes of the rotating FGM beam on the rotational speed, C-C, $n=1$, and $N^{*}=0.5$. (a) C-c, $\delta=0$, and $r=0$. (b) C-C, $\delta=8$, and $r / L=1$.

TABLE 5: The dependence of the first nondimensional frequency of the FGM beam on the axial compressive load $N^{*}$ and the volume fraction index $n, L / h=20, \delta=5, \alpha=0.2$, and $r / L=1$.

\begin{tabular}{|c|c|c|c|c|c|c|c|}
\hline \multirow{2}{*}{$\mathrm{BC}$} & \multirow{2}{*}{$N^{*}$} & \multicolumn{6}{|c|}{$N$} \\
\hline & & 0 & 0.5 & 1 & 2 & 5 & 10 \\
\hline \multirow{5}{*}{ S-S } & 0 & 0.3426 & 0.2951 & 0.2634 & 0.2459 & 0.2540 & 0.2626 \\
\hline & 0.2 & 0.3377 & 0.2885 & 0.2554 & 0.2364 & 0.2437 & 0.2522 \\
\hline & 0.4 & 0.3328 & 0.2818 & 0.2471 & 0.2264 & 0.2330 & 0.2414 \\
\hline & 0.6 & 0.3277 & 0.2749 & 0.2385 & 0.2160 & 0.2217 & 0.2299 \\
\hline & 0.8 & 0.3226 & 0.2679 & 0.2296 & 0.2050 & 0.2098 & 0.2179 \\
\hline \multirow{5}{*}{$\mathrm{C}-\mathrm{C}$} & 0 & 0.6672 & 0.5697 & 0.5086 & 0.4504 & 0.4204 & 0.4160 \\
\hline & 0.2 & 0.6641 & 0.5656 & 0.5036 & 0.4444 & 0.4133 & 0.4086 \\
\hline & 0.4 & 0.6610 & 0.5615 & 0.4986 & 0.4382 & 0.4061 & 0.4011 \\
\hline & 0.6 & 0.6579 & 0.5573 & 0.4936 & 0.4320 & 0.3988 & 0.3934 \\
\hline & 0.8 & 0.6548 & 0.5531 & 0.4885 & 0.4256 & 0.3913 & 0.3855 \\
\hline
\end{tabular}

TABLE 6: The dependence of the first nondimensional frequency of the FGM beam on the axial compressive load $N^{*}$ and $\delta, n=0.5, \alpha=0.2$, and $r / L=1$.

\begin{tabular}{|c|c|c|c|c|c|c|c|}
\hline \multirow{2}{*}{ BC } & \multirow{2}{*}{$N^{*}$} & \multicolumn{6}{|c|}{$\delta$} \\
\hline & & 0 & 2 & 5 & 10 & 15 & 20 \\
\hline \multirow{5}{*}{ S-S } & 0 & 0.2172 & 0.2320 & 0.2951 & 0.4397 & 0.5907 & 0.7389 \\
\hline & 0.2 & 0.2083 & 0.2236 & 0.2885 & 0.4351 & 0.5870 & 0.7357 \\
\hline & 0.4 & 0.1989 & 0.2149 & 0.2818 & 0.4305 & 0.5834 & 0.7326 \\
\hline & 0.6 & 0.1891 & 0.2059 & 0.2749 & 0.4258 & 0.5797 & 0.7294 \\
\hline & 0.8 & 0.1788 & 0.1964 & 0.2679 & 0.4210 & 0.5759 & 0.7262 \\
\hline \multirow{5}{*}{ C-C } & 0 & 0.5214 & 0.5296 & 0.5697 & 0.6883 & 0.8375 & 0.9963 \\
\hline & 0.2 & 0.5169 & 0.5251 & 0.5656 & 0.6850 & 0.8349 & 0.9941 \\
\hline & 0.4 & 0.5123 & 0.5206 & 0.5615 & 0.6817 & 0.8322 & 0.9918 \\
\hline & 0.6 & 0.5077 & 0.5161 & 0.5573 & 0.6783 & 0.8295 & 0.9895 \\
\hline & 0.8 & 0.5030 & 0.5115 & 0.5531 & 0.6749 & 0.8267 & 0.9873 \\
\hline
\end{tabular}


TABle 7: The dependence of the first six nondimensional frequencies of the FGM beam on the axial compressive load $N^{*}, L /$ $h=20, n=2, \delta=5, \alpha=0.2$, and $r / L=1$.

\begin{tabular}{cccccccc}
\hline BC & $N^{*}$ & \multicolumn{6}{c}{$\omega_{i}^{*}$} \\
& & $\omega_{1}^{*}$ & $\omega_{2}^{*}$ & $\omega_{3}^{*}$ & $\omega_{4}^{*}$ & $\omega_{5}^{*}$ & $\omega_{6}^{*}$ \\
\hline \multirow{4}{*}{ S-S } & 0 & 0.2459 & 0.7852 & 1.6037 & 2.6985 & 4.0216 & 5.4763 \\
& 0.4 & 0.2264 & 0.7623 & 1.5790 & 2.6733 & 3.9965 & 5.4526 \\
& 0.8 & 0.2050 & 0.7387 & 1.5540 & 2.6477 & 3.9712 & 5.4287 \\
& 1.0 & 0.1934 & 0.7267 & 1.5413 & 2.6349 & 3.9585 & 5.4167 \\
& 0 & 0.4504 & 1.1345 & 2.0846 & 3.2947 & 4.6596 & 6.0366 \\
C-C & 0.4 & 0.4382 & 1.1165 & 2.0641 & 3.2731 & 4.6382 & 6.0169 \\
& 0.8 & 0.4256 & 1.0982 & 2.0434 & 3.2515 & 4.6167 & 5.9972 \\
& 1.0 & 0.4192 & 1.0889 & 2.0330 & 3.2406 & 4.6060 & 5.9873 \\
\hline
\end{tabular}

TABLE 8: The dependence of the first nondimensional frequency of the FGM beam on $L / h$ and $\alpha, n=0.2, N^{*}=0.5, \delta=5, \lambda_{0}=10^{-3}$, and $r / L=1$.

\begin{tabular}{cccccccc}
\hline \multirow{3}{*}{ BC } & $\alpha$ & \multicolumn{6}{c}{$L / h$} \\
& & 5 & 10 & 20 & 40 & 60 & 80 \\
\hline \multirow{6}{*}{ S-S } & 0 & 0.9198 & 0.5099 & 0.3079 & 0.2274 & 0.2089 & 0.2036 \\
& 0.1 & 0.9224 & 0.5113 & 0.3087 & 0.2285 & 0.2105 & 0.2057 \\
& 0.2 & 0.9255 & 0.5130 & 0.3097 & 0.2297 & 0.2124 & 0.2083 \\
& 0.3 & 0.9292 & 0.5150 & 0.3109 & 0.2312 & 0.2146 & 0.2114 \\
& 0.4 & 0.9337 & 0.5174 & 0.3124 & 0.2331 & 0.2175 & 0.2152 \\
& 0.5 & 0.9393 & 0.5205 & 0.3142 & 0.2355 & 0.2210 & 0.2201 \\
& 0 & 1.8663 & 1.0958 & 0.6052 & 0.3653 & 0.2990 & 0.2722 \\
& 0.1 & 1.8805 & 1.1039 & 0.6094 & 0.3680 & 0.3016 & 0.2751 \\
& 0.2 & 1.8975 & 1.1135 & 0.6145 & 0.3712 & 0.3047 & 0.2785 \\
C-C & 0.3 & 1.9181 & 1.1253 & 0.6207 & 0.3751 & 0.3084 & 0.2826 \\
& 0.4 & 1.9437 & 1.1399 & 0.6283 & 0.3799 & 0.3132 & 0.2878 \\
& 0.5 & 1.9764 & 1.1585 & 0.6382 & 0.3862 & 0.3192 & 0.2945 \\
\hline
\end{tabular}

TABLE 9: The dependence of the first nondimensional frequency of the FGM beam on $L / h$ and $\delta, n=0.2, \alpha=0.2, N^{*}=0.5, \lambda_{0}=10^{-3}$, and $r / L=1$.

\begin{tabular}{cccccccc}
\hline BC & $\delta$ & \multicolumn{6}{c}{$L / h$} \\
\cline { 3 - 8 } 5 & 10 & 20 & 40 & 60 & 80 \\
& 0 & 0.9048 & 0.4740 & 0.2413 & 0.1328 & 0.1107 & 0.1101 \\
& 2 & 0.9082 & 0.4805 & 0.2538 & 0.1541 & 0.1350 & 0.1341 \\
S-S & 5 & 0.9255 & 0.5130 & 0.3097 & 0.2297 & 0.2124 & 0.2083 \\
& 10 & 0.9844 & 0.6119 & 0.4452 & 0.3733 & 0.3502 & 0.3397 \\
& 15 & 1.0733 & 0.7411 & 0.5911 & 0.5133 & 0.4828 & 0.4664 \\
& 0 & 1.8857 & 1.0916 & 0.5730 & 0.2993 & 0.2161 & 0.1833 \\
& 2 & 1.8876 & 1.0952 & 0.5799 & 0.3124 & 0.2336 & 0.2033 \\
C-C & 5 & 1.8975 & 1.1135 & 0.6145 & 0.3712 & 0.3047 & 0.2785 \\
& 10 & 1.9324 & 1.1758 & 0.7203 & 0.5154 & 0.4561 & 0.4279 \\
& 15 & 1.9884 & 1.2700 & 0.8588 & 0.6716 & 0.6088 & 0.5745 \\
\hline
\end{tabular}

increasing the porosity ratio of the material, both mass and stiffness of the structure decrease; however, the stiffness of the beam decreases sharply than the decrease of the mass. This also means that the porosity ratio is a parameter to control the vibration of the FGM beam; in other words, changing the porosity ratio will change the working performance of the structure.
TABLE 10: The dependence of the first nondimensional frequency of the FGM beam on $L / h$ and $\alpha, n=0.2, N^{*}=0.5, \alpha=0.2, \delta=5$, $\lambda_{0}=10^{-3}$, and $r / L=1$.

\begin{tabular}{cccccccc}
\hline BC & $\omega_{i}^{*}$ & \multicolumn{6}{c}{$L / h$} \\
& & 5 & 10 & 20 & 40 & 60 & 80 \\
\hline \multirow{6}{*}{ S-S } & $\omega_{1}^{*}$ & 0.9255 & 0.5130 & 0.3097 & 0.2297 & 0.2124 & 0.2083 \\
& $\omega_{2}^{*}$ & 3.3353 & 1.9643 & 1.0847 & 0.6564 & 0.5395 & 0.4935 \\
& $\omega_{3}^{*}$ & 6.1553 & 4.1398 & 2.3247 & 1.3095 & 0.9985 & 0.8648 \\
& $\omega_{4}^{*}$ & 8.4406 & 6.7814 & 3.9891 & 2.2047 & 1.6138 & 1.3447 \\
& $\omega_{5}^{*}$ & 9.8942 & 9.6033 & 6.0151 & 3.3032 & 2.2350 & 1.6755 \\
& $\omega_{6}^{*}$ & 10.7814 & 10.2823 & 6.7829 & 3.4187 & 2.4060 & 1.9483 \\
& $\omega_{1}^{*}$ & 1.8975 & 1.1135 & 0.6145 & 0.3712 & 0.3047 & 0.2785 \\
& $\omega_{2}^{*}$ & 4.4666 & 2.9041 & 1.6229 & 0.9189 & 0.7054 & 0.6140 \\
$\mathrm{C}-\mathrm{C}$ & $\omega_{3}^{*}$ & 6.7845 & 5.1651 & 3.0493 & 1.6945 & 1.2469 & 1.0439 \\
& $\omega_{4}^{*}$ & 8.7909 & 7.8311 & 4.8739 & 2.7061 & 1.9436 & 1.5828 \\
& $\omega_{5}^{*}$ & 10.0453 & 10.3811 & 6.9602 & 3.9304 & 2.7900 & 2.2308 \\
& $\omega_{6}^{*}$ & 10.8840 & 10.8069 & 9.2402 & 5.3271 & 3.7602 & 2.9688 \\
\hline
\end{tabular}

\section{Conclusions}

By using the new shear deformation theory type of hyperbolic sine functions, finite element formulations for free vibration analysis of rotating FGM beams resting on twoparameter elastic foundations are established in this paper, in which the initial geometrical imperfection and the porosity of the material are considered. Based on the numerical results, some important novel explorations are drawn as follows:

The rotational speed has a significant effect on the free vibration response as well as the vibration mode shape of the structures. When the rotational speed increases, the frequencies of the beam increase, especially the first frequency, and the vibration mode shape is no longer symmetrical through position $x=L / 2$.

As the axial compressive load value increases, the frequency decreases, and the strongest change manifests itself at the first frequency as the axial load increases.

When reducing the beam thickness and the porosity ratio, the frequencies of the FGM beam are reduced.

\section{Data Availability}

The data used to support the findings of this study are included within the article.

\section{Conflicts of Interest}

The author declares that there are no conflicts of interest regarding the publication of this paper.

\section{Acknowledgments}

This work was supported by the University of Transport Technology Foundation for Science and Technology Development (Grant no. 1139/QD-DHCNGTVT). 


\section{References}

[1] H. Saito and K. Otomi, "Vibration and stability of elastically supported beams carrying an attached mass under axial and tangential loads," Journal of Sound and Vibration, vol. 62, no. 2, pp. 257-266, 1979.

[2] E. Esmailzadeh and A. R. Ohadi, "Vibration and stability analysis of non-uniform Timoshenko beams under axial and distributed tangential loads," Journal of Sound and Vibration, vol. 236, no. 3, pp. 443-456, 2000.

[3] J. M. Sloss, J. C. Bruch, I. S. Sadek, and S. Adali, "Piezo patch sensor/actuator control of the vibrations of a cantilever under axial load," Composite Structures, vol. 62, no. 3-4, pp. 423-428, 2003.

[4] Y. Zhang, G. Liu, and X. Han, "Transverse vibrations of double-walled carbon nanotubes under compressive axial load," Physics Letters A, vol. 340, no. 1-4, pp. 258-266, 2005.

[5] S. A. Alkharabsheh and M. I. Younis, "Statics and dynamics of MEMS arches under axial forces," Journal of Vibration and Acoustics, vol. 135, no. 2, p. 021007, 2013.

[6] E. Babilio, "Dynamics of an axially functionally graded beam under axial load," The European Physical Journal Special Topics, vol. 222, no. 7, pp. 1519-1539, 2013.

[7] O. R. Barry, Y. Zhu, J. W. Zu, and D. C. D. Oguamanam, "Free vibration analysis of a beam under axial load carrying a massspring-mass," in Proceedings of the ASME 2012 International Design Engineering Technical Conferences \& Computers and Information in Engineering Conference, pp. 791-796, September 2013, DETC2012-70144.

[8] H. Farokhi and M. H. Ghayesh, "Nonlinear motion characteristics of microarches under axial loads based on modified couple stress theory," Archives of Civil and Mechanical Engineering, vol. 15, no. 2, pp. 401-411, 2015.

[9] A. Ghannadiasl and M. Mofid, "An analytical solution for free vibration of elastically restrained Timoshenko beam on an arbitrary variable winkler foundation and under axial load," Latin American Journal of Solids and Structures, vol. 12, no. 13, pp. 2417-2438, 2015.

[10] M. Nejati, A. Eslampanah, and M. Najafizadeh, "Buckling and vibration analysis of functionally graded carbon nanotubereinforced beam under axial load," International Journal of Applied Mechanics, vol. 8, no. 1, p. 1650008, 2016.

[11] P. V. Thuc, H. T. Thai, and M. Aydogdu, "Free vibration of axially loaded composite beams using a four-unknown shear and normal deformation theory," Composite Structures, vol. 178, pp. 406-414, 2017.

[12] S. Waddar, J. Pitchaimani, M. Doddamani, and E. Barbero, "Buckling and vibration behaviour of syntactic foam core sandwich beam with natural fiber composite facings under axial compressive loads," Composites Part B: Engineering, vol. 175, p. 107133, 2019.

[13] X. Zhao, B. Chen, Y. H. Li, W. D. Zhu, F. J. Nkiegaing, and Y. B. Shao, "Forced vibration analysis of Timoshenko doublebeam system under compressive axial load by means of Green's functions," Journal of Sound and Vibration, vol. 464, p. 115001, 2020.

[14] C. Szymczak and M. Kujawa, "Sensitivity analysis of free torsional vibration frequencies of thin-walled laminated beams under axial load," Continuum Mechanics and Thermodynamics, vol. 32, no. 5, pp. 1347-1356, 2020.

[15] D. Xu, J. Du, and C. Tian, "Vibration characteristics and power flow analyses of a ship propulsion shafting system with general support and thrust loading," Shock and Vibration, vol. 2020, Article ID 3761590, 13 pages, 2020.
[16] A. E. Brahimi-Mamaghani, A. Forooghi, H. Sarparast, A. Alibeigloo, and M. I. Friswell, "Vibration of viscoelastic axially graded beams with simultaneous axial and spinning motions under an axial load," Applied Mathematical Modelling, vol. 90, pp. 131-150, 2021.

[17] S. Khosravi, H. Arvin, and Y. Kiani, "Vibration analysis of rotating composite beams reinforced with carbon nanotubes in thermal environment," International Journal of Mechanical Sciences, vol. 164, p. 105187, 2019.

[18] S. Khosravi, H. Arvin, and Y. Kiani, "Interactive thermal and inertial buckling of rotating temperature-dependent FG-CNT reinforced composite beams," Composites Part B: Engineering, vol. 175, p. 107178, 2019.

[19] Y. Kiani, H. Bagheri, and M. R. Eslami, "Asymmetric compressive stability of rotating annular plates," European Journal of Computational Mechanics, vol. 28, no. 4, pp. 325-350, 2019.

[20] H. Arvin, S. M. H. Hosseini, and Y. Kiani, "Free vibration analysis of pre/post buckled rotating functionally graded beams subjected to uniform temperature rise," Thin-Walled Structures, vol. 158, p. 107187, 2021.

[21] H. Bagheri, Y. Kiani, and M. R. Eslami, "Asymmetric thermoinertial buckling of annular plates," Acta Mechanica, vol. 228, no. 4, pp. 1493-1509, 2017.

[22] S. M. H. Hosseini, H. Arvin, and Y. Kiani, "On buckling and post-buckling of rotating clamped-clamped functionally graded beams in thermal environment," Mechanics Based Design of Structures and Machines, pp. 1-16, 2020.

[23] C. Bedon, M. Fasan, and C. Amadio, "Vibration analysis and dynamic characterization of structural glass elements with different restraints based on operational modal analysis," Buildings, vol. 9, no. 1, p. 13, 2019.

[24] C. Bedon, "Issues on the vibration analysis of in-service laminated glass structures: analytical, experimental and numerical investigations on delaminated beams," Applied Sciences, vol. 9, no. 18, p. 3928, 2019.

[25] M. Guellil, H. Saidi, F. Bourada et al., "Influences of porosity distributions and boundary conditions on mechanical bending response of functionally graded plates resting on Pasternak foundation," Steel and Composite Structures, vol. 38, no. 1, pp. 1-15, 2021.

[26] T. H. L. Bekkaye, B. Fahsi, A. A. Bousahla et al., "Porositydependent mechanical behaviors of FG plate using refined trigonometric shear deformation theory," Computers and Concrete, vol. 26, no. 5, pp. 439-450, 2020.

[27] M. S. H. Al-Furjan, A. hatami, M. Habibi, L. Shan, and A. Tounsi, "On the vibrations of the imperfect sandwich higher-order disk with a lactic core using generalize differential quadrature method," Composite Structures, vol. 257, p. 113150, 2021.

[28] A. Zine, A. A. Bousahla, F. Bourada et al., "Bending analysis of functionally graded porous plates via a refined shear deformation theory," Computers and Concrete, vol. 26, no. 1, pp. 63-74, 2020.

[29] M. Kaddari, A. Kaci, A. A. Bousahla et al., "A study on the structural behaviour of functionally graded porous plates on elastic foundation using a new quasi-3D model: bending and free vibration analysis," Computers and Concrete, vol. 25, no. 1, pp. 37-57, 2020.

[30] F. YAddou, M. Meradjah, A. A. Bousahla et al., "Influences of porosity on dynamic response of FG plates resting on Winkler/Pasternak/Kerr foundation using quasi 3D HSDT," Computers and Concrete, vol. 24, no. 4, pp. 347-367, 2019.

[31] M. Medani, A. Benahmed, Z. Mohamed, H. Heireche, A. Tounsi, A. A. Bousahla et al., "Static and dynamic behavior 
of (FG-CNT) reinforced porous sandwich plate using energy principle," Steel and Composite Structures, vol. 32, no. 5, pp. 595-610, 2019.

[32] H. Berghouti, E. A. A. Bedia, A. Benkhedda, and A. Tounsi, "Vibration analysis of nonlocal porous nanobeams made of functionally graded material," Advances in Nano Research, vol. 7, no. 5, pp. 351-364, 2019.

[33] T. Q. Bui, T. V. Do, L. H. T. Ton et al., "On the high temperature mechanical behaviors analysis of heated functionally graded plates using FEM and a new third-order shear deformation plate theory," Composites Part B: Engineering, vol. 92, pp. 218-241, 2016.

[34] H.-N. Nguyen, T. C. Tan, D. T. Luat, V.-D. Phan, D. V. Thom, and P. V. Minh, "Research on the buckling behavior of functionally graded plates with stiffeners based on the thirdorder shear deformation theory," Materials, vol. 12, no. 8, p. 1262, 2019.

[35] V. N. Hoai, D. H. Doan, N. M. Khoa, T. Van Do, and H. T. Tran, "Phase-field buckling analysis of cracked stiffened functionally graded plates," Composite Structures, vol. 217, pp. 50-59, 2019.

[36] H. L. Ton-That, "A combined strain element to functionally graded structures in thermal environment," Acta Polytechnica, vol. 60 , no. 6 , pp. 528-539, 2020.

[37] H. L. Ton-That, "A new C0 third-order shear deformation theory for the nonlinear free vibration analysis of stiffened functionally graded plates," Facta Universitatis, Series: Mechanical Engineering, pp. 1-21, 2020.

[38] H. Nguyen-Van, H. L. Ton-That, T. Chau-Dinh, and N. D. Dao, "Nonlinear static bending analysis of functionally graded plates using MISQ24 elements with drilling rotations," International Conference on Advances in Computational Mechanics, pp. 461-475, 2017.

[39] K. P. Soldatos, "A transverse shear deformation theory for homogeneous monoclinic plates," Acta Mechanica, vol. 94, no. 3-4, pp. 195-220, 1992.

[40] T. Huu-Tai and C. Dong-Ho, "Finite element formulation of various four unknown shear deformation theories for functionally graded plates," Finite Elements in Analysis and Design, vol. 75, pp. 50-61, 2013.

[41] S. P. Timoshenko and J. M. Gere, Theory of Elastic Stability, Dover Publications, New York, NY, USA, 1989.

[42] C. Dejin, F. Kai, and Z. Shijie, "Flapwise vibration analysis of rotating composite laminated Timoshenko microbeams with geometric imperfection based on a re-modified couple stress theory and isogeometric analysis," European Journal of Mechanics-A/Solids, vol. 76, pp. 25-35, 2019.

[43] F. Y. Cheng and C. P. Pantelides, "Dynamic Timoshenko beam-columns on elastic media," Journal of Structural Engineering, vol. 114, no. 7, pp. 1524-1550, 1988.

[44] A. Bokaian, "Natural frequencies of beams under compressive axial loads," Journal of Sound and Vibration, vol. 126, no. 1, pp. 49-65, 1988.

[45] T. Yokoyama, "Vibration analysis of Timoshenko beamcolumns on two-parameter elastic foundations," Computers \& Structures, vol. 61, no. 6, pp. 995-1007, 1996.

[46] N. Wattanasakulpong and A. Chaikittiratana, "Flexural vibration of imperfect functionally graded beams based on Timoshenko beam theory: Chebyshev collocation method," Meccanica, vol. 50, no. 5, pp. 1331-1342, 2015.

[47] M. Avcar and W. KMM, "Free vibration of functionally graded beams resting on Winkler-Pasternak foundation," Arabian Journal of Geosciences, vol. 11- 232, pp. 1-8, 2018.
[48] M. H. Ghayesh and M. Amabili, "Coupled longitudinaltransverse behaviour of a geometrically imperfect microbeam," Composites Part B: Engineering, vol. 60, pp. 371-377, 2014.

[49] A. D. Wright, C. E. Smith, R. W. Thresher, and J. L. C. Wang, "Vibration modes of centrifugally stiffened beams," Journal of Applied Mechanics, vol. 49, no. 1, pp. 197-202, 1982.

[50] H. H. Yoo and S. H. Shin, "Vibration analysis of rotating cantilever beams," Journal of Sound and Vibration, vol. 212, no. 5, pp. 807-828, 1998. 